
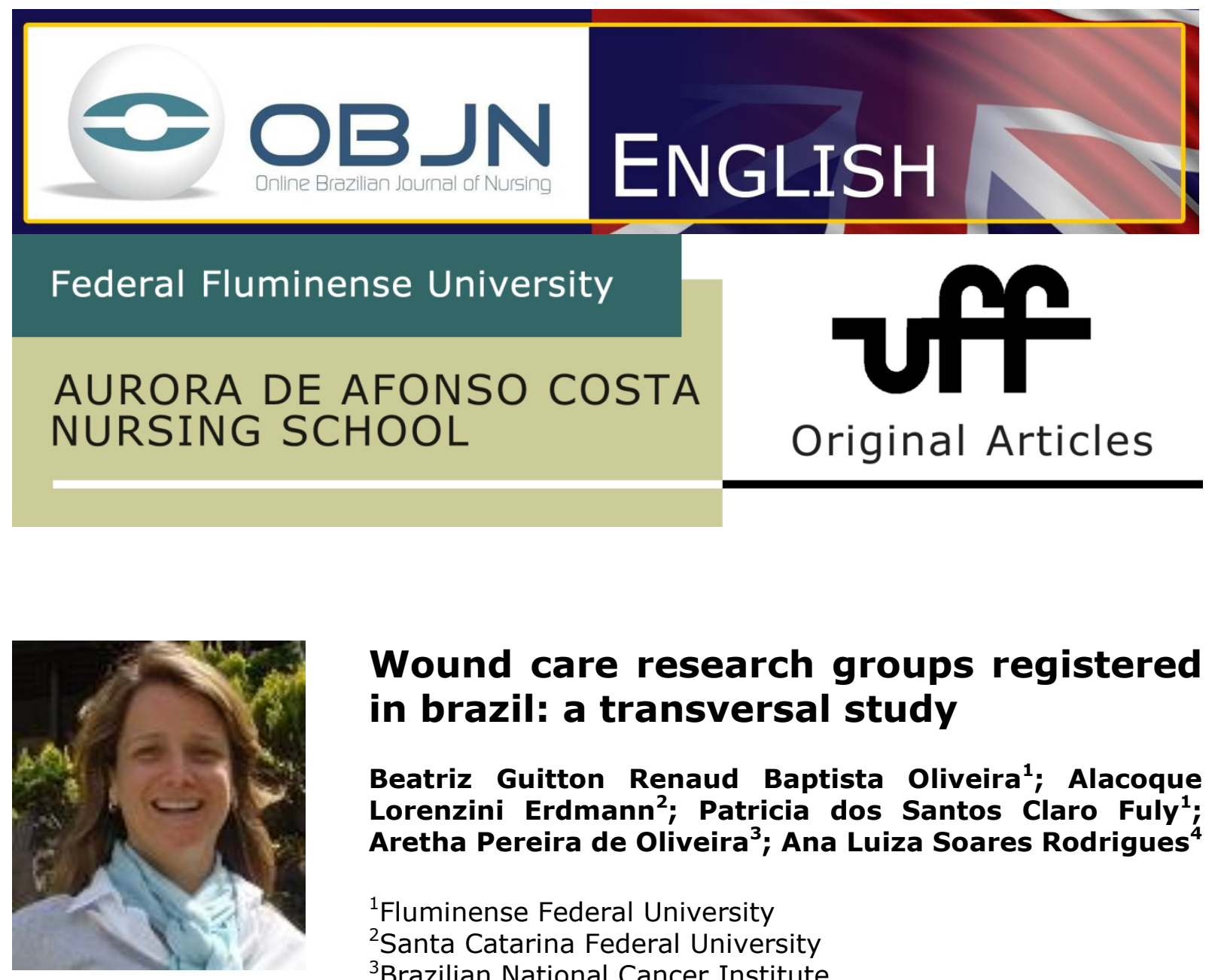

\title{
Wound care research groups registered in brazil: a transversal study
}

\author{
Beatriz Guitton Renaud Baptista Oliveira ${ }^{1}$; Alacoque \\ Lorenzini Erdmann ${ }^{2}$; Patricia dos Santos Claro Fuly ${ }^{1}$; \\ Aretha Pereira de Oliveira $^{3}$; Ana Luiza Soares Rodrigues ${ }^{4}$ \\ ${ }^{1}$ Fluminense Federal University \\ ${ }^{2}$ Santa Catarina Federal University \\ ${ }^{3}$ Brazilian National Cancer Institute \\ ${ }^{4}$ Lagoa Federal Hospital
}

\begin{abstract}
Aim: to describe the main characteristics of Brazilian nursing and health groups registered in the Research Group Directory in Brazil involved in the study of wound care. Method: This is a documentary study which adopts a transversal approach, performed between March 3rd and April 10th 2012, with information collected from research groups that study wound care.

Results: Of the 61 selected groups, $42.6 \%$ are located in the Southeast region of Brazil; only $44.26 \%$ of the groups have nursing staff involved. The majority of the group leaders are medical doctors; $78.7 \%$ of the groups have developed up to seven lines of research. Of these, $31.8 \%$ of the lines of research focus on histopathology and wound healing. Conclusion: Nursing staff develop many lines of research in the area of assistance and quality of life, but there is a significant paucity of research based on an interdisciplinary context.
\end{abstract}

Keywords: Wound Healing; Research Groups; Nursing. 


\section{INTRODUCTION}

Since the 1980s, Brazilian nursing staff have made efforts to publicize books and articles regarding prevention of injuries and wound care. Compared with a lower level of production in the past, nursing staff, in the last decade, have considerably widened the extent of knowledge of this area, dealing not only with the descriptive aspects of the physiology of lesions and bandage techniques, but also have dealt with emerging topics such as the description of new technological resources to repair injuries, the management of nursing, the economic and epidemiological aspects that involve wounds, the development of human resources, the use of complementary therapies, and discussions of professional autonomy.

Studies related to the topic of wound care are really important considering that some types of wounds such as leg ulcers, for example, are a public health issue nowadays ${ }^{(1)}$. Such studies reveal the nature of the work of nursing staff in terms of wound prevention and treatment, and cross-over questions such as professional autonomy and economy in health.

There are groups dedicated to research into wound care in Brazil that include other areas beyond nursing. The scientific production and capacitation of new researchers is supported in such research groups. These groups are organized in such a way as to operate projects linked to the lines of research within a particular scope of knowledge that identifies each Research Group ${ }^{(2)}$.

There is a growing potential in research groups dedicated to this topic, and an increase of scientific production on the part of these groups, that is based on the actual Brazilian economic scenario and the progressive technological advance in the medical industry. Such facts lead to the development of innovative products to prevent injuries and treat wounds.

Oliveira BGRB, Erdmann AL, Fuly PSC, Oliveira AP, Rodrigues ALS. Wound care research groups registered in Brazil: a transversal study. Online braz j nurs [Internet]. 2013 June [cited year mouth day]; 12 (2): 307-18. Available from: http://www.objnursing.uff.br/index.php/nursing/article/view/3988. doi: http://dx.doi.org/10.5935/1676- 
With regard to this proposal, an attempt will be made to recognize the expertise and the productivity of the researchers in the topic of wound care by checking the Research Groups Directory in Brazil, registered by the Brazilian National Council for Scientific and Technological Development (CNPq, in Portuguese).

The Directory is an instrument for exchange and information sharing. It is a source for study and census data collection about groups, scholarships and interactions between the groups and the manufacturing sector. In addition, it represents an instrument to preserve a record of scientific-technology activity in Brazil ${ }^{(3)}$.

Considering the described context, this study centers on the question: What are the characteristics of the Brazilian nursing and health groups registered in the Directory of CNPq that undertake research into wound care?

To respond to the research question, the following objective has also been set: to describe the main characteristics of the Brazilian groups of nursing and health that research wound care, registered in the Directory of Research Groups of CNPq.

\section{METHOD}

This is a documentary study which adopts a transversal approach. It uses data with regard to research groups in Brazil that study wound care and are registered in the Research Groups Directory. These data are available in the CNPq website, and were accessed through an investigation using the search option "groups".

The search was performed between March 3rd and April 10th 2012 using the following search keywords, in portuguese: wounds; wounds nursing; skin injuries; cicatrization; tissue lesions; wound healing. This search found 233 groups: 55 with the word wounds; 21 with the words wounds nursing; 17 with the words skin lesion; 113 with the word 
cicatrization; one with the words tissue lesions and 26 with the words wound cicatrization.

The inclusion criteria with regard to the groups were that they must be registered groups in the CNPq Directory, nursing groups or from other areas of knowledge, groups with a research focus on chronic or acute wounds, or those whose leaders have any publication(s) in this area of study.

The exclusion criteria with regard to the groups were no line of research regarding wounds and wound healing, groups from odontology, as they only present lines of research related to dental cicatrization, groups that had studies exclusively focused on animals, groups that dealt with the cicatrization of organs, except skin or muscles, groups whose latest update was prior to June 2010 or whose latest update of the scientific CV of the leader was prior to June 2010. Groups found to be associated with two or more keywords were considered only once.

After the application of the inclusion and exclusion criteria, 61 groups remained and were selected. They were then submitted to an analysis of specific elements defined previously in order to build a data bank. The variables of analysis were: identification data - year started; university support/state; last update; predominant area of knowledge; participation of nurses; data of the group leader (academic title/area of knowledge); number of researchers/academic title; number of students/academic title; number of technicians; lines of research; repercussions of the work of the group; relationship with the productive sector; characterization of the study object of the leader; group projects; group production; investigation methods.

During the evaluation of the groups, it was perceived that a large number of lines of research were in development. From a total of 347 lines of research, 88 are related to the topic of wounds. Based on the large number of lines of research found, working with many different objects of study, it was decided to organize the lines of research related Oliveira BGRB, Erdmann AL, Fuly PSC, Oliveira AP, Rodrigues ALS. Wound care research groups registered in Brazil: a 310 transversal study. Online braz j nurs [Internet]. 2013 June [cited year mouth day]; 12 (2): 307-18. Available from: http://www.objnursing.uff.br/index.php/nursing/article/view/3988. doi: http://dx.doi.org/10.5935/1676- 
to wounds in categories, in order to better analyze the production of the groups and the main types of research undertaken.

The presentation of the results was done in a descriptive manner, with the combination of the lines of research related to wounds of each group in seven categories of study: pre-clinical studies; wound histopathological studies; studies of technologies to treat wounds; studies of mucocutaneous lesions caused by endemic diseases; epidemiologic studies about wounds; studies about nursing care and quality of life of patients with wounds; studies of oncologic lesions.

In order to discuss the data so obtained, it was decided to organize the information gathered in charts and spreadsheets, to better visualize the presentation.

\section{RESULTS}

The sample is composed by 61 groups and 88 lines of research. Regarding the origin of the selected groups in terms of their geographical region, $42.6 \%$ of them are located in Southeast Brazil, as can be observed on chart 1. 
Chart1: Distribution of groups of research in wounds by region in Brazil. B razil, 2012

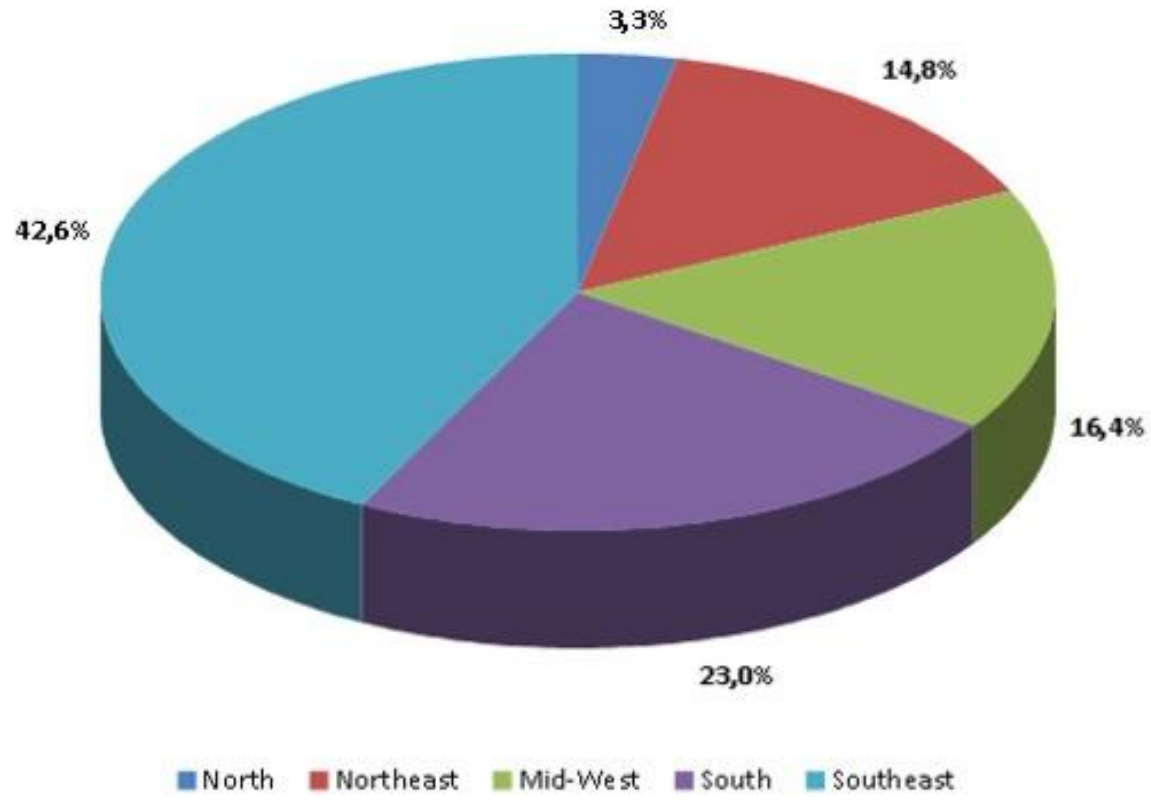

Source: Database of the Directory of Groups of Research of CNPq

In terms of the participation of nurses in the research groups that study wounds, it was observed that, of the 61 groups registered in CNPq Directory, only $27(44.26 \%)$ had nurses as members of the group.

As the selected groups are all researching wounds, a survey was conducted about the group leaders regarding their academic titles and area of knowledge. This analysis demonstrated that the majority of leaders are medical doctors, as shown on spreadsheet 1 below.

Spreadsheet 1: Academic title and area of knowledge of the leaders of groups of research in wounds. Brazil, 2012

\begin{tabular}{ccccc}
\hline Area of knowledge & \multicolumn{5}{c}{ Academic Title } \\
\hline Nursing & Post-Doctor & Doctor & Master & Specialist \\
\cline { 2 - 5 } Medicine & 2 & 12 & 3 & 1 \\
Biological Sciences & 5 & 20 & 0 & 0 \\
Pharmacy & 3 & 3 & 0 & 0 \\
Others & 0 & 3 & 1 & 0 \\
\hline Total & 14 & 41 & 5 & 0 \\
\hline$\%$ & 23.0 & 67.2 & 8.2 & 1.6 \\
\hline
\end{tabular}

Source: Database of the Directory of Groups of Research of CNPq

Oliveira BGRB, Erdmann AL, Fuly PSC, Oliveira AP, Rodrigues ALS._Wound care research groups registered in Brazil: a transversal study. Online braz j nurs [Internet]. 2013 June [cited year mouth day]; 12 (2): 307-18. Available from: http://www.objnursing.uff.br/index.php/nursing/article/view/3988. doi: $\underline{\text { http://dx.doi.org/10.5935/1676- }}$ 
It was also seen that, of the 27 groups that involve the participation of nurses, 20 of them have these professionals as leaders.

At the same time, it was identified that the main areas of knowledge of the research groups, as highlighted from the CNPq Directory, were in the medical area, as listed in spreadsheet 2 .

Spread sheet 2: Predominant areas of knowedge of the groups of research in wounds. Brazil, 2012

\begin{tabular}{ccc}
\hline Area of knowledge & $\mathrm{n}$ & $\%$ \\
\hline Nursing & 18 & 29.5 \\
Medicine & 23 & 37.8 \\
Pharmacy & 4 & 6.5 \\
Collective Health & 4 & 6.5 \\
Others & 12 & 19.7 \\
\hline Total & 61 & 100 \\
\hline
\end{tabular}

Source: Database of the Directory of Groups of Research of CNPq

Regarding the year started, it can be seen that there has been a crescent development throughout the years, with a noteable rise in the number of groups in the first decade of 2000, as observed on chart 2.

Chart 2: Starting year of the groups of research in wounds. Brazil, 2012

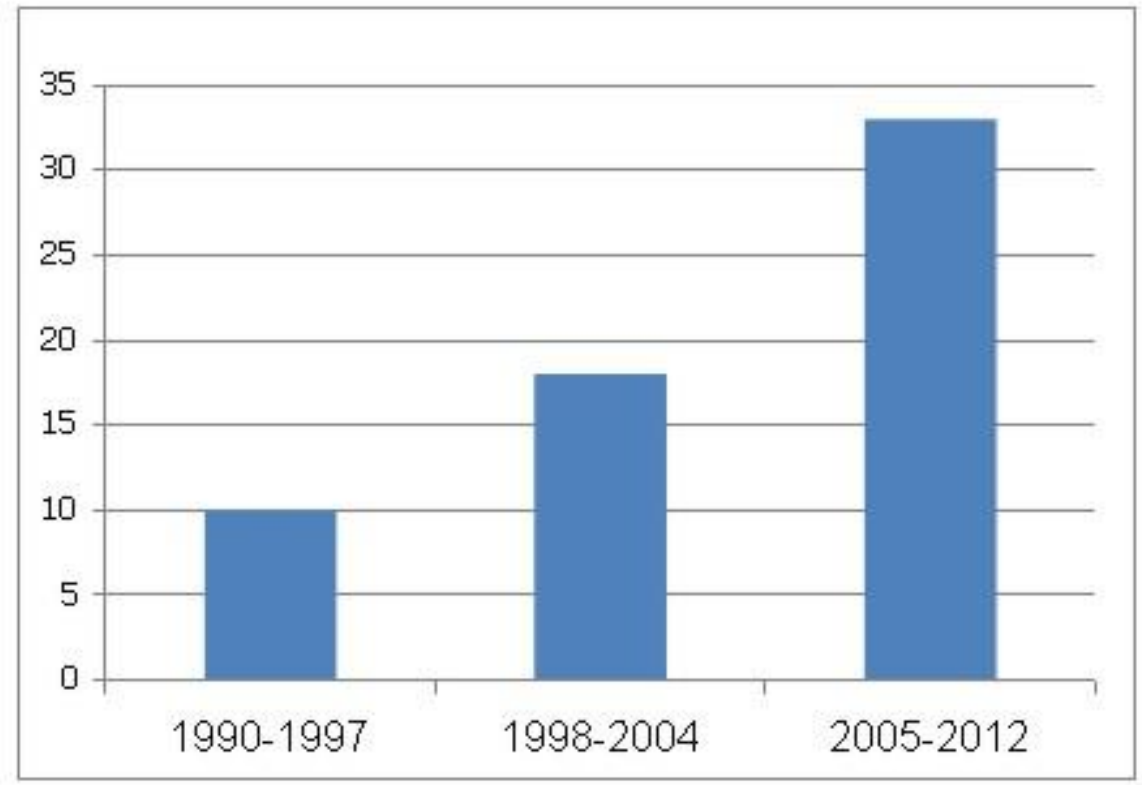

Source: Database of the Directory of Groups of Research of CNPq 
The four oldest groups in the sample started in the year 1990, matching the period there is a disclosure of results of studies from the 1980's decade. The most recent group was set up at the beginning of 2012 .

To divide into the groups into categories, we undertook an evaluation of the lines of research developed by each group. The majority of the groups $(93.4 \%)$ present more than one line of research, and $79.7 \%$ develop between one and seven lines, as a demonstration of high specificity of the studied objects, as seen on spreadsheet 3.

Spreadsheet 3: Number of lines of study per group of research in wounds. Brazil, 2012

\begin{tabular}{ccc}
\hline Number of lines of study & Number of groups of research & $\%$ \\
\hline $1-7$ & 48 & 78.7 \\
$8-15$ & 9 & 14.7 \\
$16-22$ & 4 & 6.6 \\
\hline Total & 61 & 100 \\
\hline
\end{tabular}

Source: Database of the Directory of Groups of Research of CNPq

From the total of 347 lines of research developed by these groups, 88 of them were selected in that they dealt with the topic of wounds. It can be seen however, that the majority of the groups have developed studies about a range of different objects and include aspects related to tissue damage.

The lines of research selected were divided into categories for further evaluation based on the types of research most commonly engaged in by the groups. The results are summarized on spreadsheet 4.

Spreadsheet 4: Distribution of absolute frequency of lines of study by categories. Brazil, 2012

\begin{tabular}{lcc}
\hline \multicolumn{1}{c}{ Category } & $n$ & $\%$ \\
\hline Pre-clinical studies & 3 & 3,3 \\
Histopathological studies and wound cicatrization & 28 & 31,8 \\
Studies of technologies for the treatment of wounds & 21 & 23,9 \\
Epidemiological studies of wounds & 6 & 6,8 \\
Studies about nursing care and quality of life of patients with wounds & 21 & 23,9 \\
Studies of mucocutaneous lesions caused by endemic diseases & 7 & 8,0 \\
Studies of oncologic lesions & 2 & 2,3 \\
\hline Total & 88 & 100 \\
\hline
\end{tabular}

Source: Database of the Directory of Groups of Research of $\mathrm{CNPq}$ 
We can observe, by an analysis of spreadsheet 4 , that the most common categories are histopathological studies and wound healing, the studies of technologies for the treatment of wounds, and studies about the nursing care and the quality of life of patients with wounds, respectively.

On spreadsheet 5 , it can be seen that the majority of the studies in the medical area involve histopathological evaluation and the wound healing; on the other hand, the studies involving nursing are mainly related to nursing care and the quality of life of patient with wounds.

Spreadsheet 5: Distribution of categories of study per areas of knowledge, Brazil, 2012

\begin{tabular}{|c|c|c|c|c|c|}
\hline \multirow[b]{2}{*}{ Category } & \multicolumn{5}{|c|}{ Area of knowledge } \\
\hline & Nursing & Medicine & Pharmacy & Colle ctive Heatth & Others \\
\hline Pre-cinical studies & & & 1 & & 2 \\
\hline Histopathological studies and wound cicatrization & 2 & 23 & & & 2 \\
\hline Studies of technologies for the treatment of wounds & 6 & 4 & 5 & & 7 \\
\hline Epidemiological studies of wounds & 3 & 3 & & & \\
\hline Studies about nursing care and quality of life of patients with wounds & 17 & & & 3 & 1 \\
\hline Studies of mucocutaneous lesions caused by endemic diseases & & 3 & & 1 & 3 \\
\hline Studies of oncologic lesions & 1 & & 1 & & \\
\hline
\end{tabular}

Source: Database of the Directory of Groups of Research of CNPq

It is important to highlight that public health also presents lines of research related to the topic of wounds, as the presence of nurse-researchers is particularly high in those groups. The studies regarding epidemiology are divided between the nursing and medicine groups, and the ones regarding the technologies for the treatment of wounds are developed by researchers from many areas of knowledge, without the identification of a specific scientific focus.

\section{DISCUSSION}

A study group is the locus of knowledge production and the formation of human resources for research ${ }^{(4)}$. Despite the fact that these groups represent a powerful strategy for strengthening nursing as a science and as a profession, nursing still needs to amplify its investigative spectrum, in view of the fact that the results of this study point Oliveira BGRB, Erdmann AL, Fuly PSC, Oliveira AP, Rodrigues ALS. Wound care research groups registered in Brazil: a transversal study. Online braz j nurs [Internet]. 2013 June [cited year mouth day]; 12 (2): 307-18. Available from: http://www.objnursing.uff.br/index.php/nursing/article/view/3988. doi: http://dx.doi.org/10.5935/1676- 
to a large advantage when there are study groups led by professionals and lines of research from other areas, but not nursing.

Considering the expression of the professional activities performed by nursing staff and their relationship with the topic of wounds based on the multitude of research scenarios that nurses can deal with, there is a vast universe to be occupied by Brazilian professional nurses. Despite the fact that wound treatment is performed essentially by nurses, it represents a field and a praxis that is multiprofessional. However, interdisciplinary action is as yet incipient, due to the difficulty of nursing staff overcoming their own discursive principles ${ }^{(5)}$.

This study demonstrates that nurses have not participated actively in interdisciplinary research, given that the specialism of nursing is present in only seven study groups in other areas, as well as there being 41 groups that nurses do not lead. This low integration of research in other areas is reflected, most of all, in studies of technological innovation, even though this area presents a high tendency to interdisciplinarity, with cooperation from areas such as pharmacy, biology and biomedicine.

Considering also that nursing staff do not participate in any study group involved in the development of pre-clinical studies, it clearly denotes the need for involvement with regard to techniques that are linked to this type of research. One fact that can justify such a result comes from the process of the education of nurse-researchers in Brazil, as a result of which the majority achieve a doctorate in an area that supports not only basic but also experimental research ${ }^{(6)}$.

Another relevant factor is present in the nature of the studies performed by nursing staff, essentially concentrated in the category studies about nursing care and the quality of life of patients with wounds. The studies that appear this category are quite heterogeneous, with topics that vary from the education in health, through bioethics, up to nursing diagnosis and lesion treatment. The care associate with ostomy and specifically mentioned wounds are dominant terminologies among the described keywords. When 
analyzing this category, it can be seen that there is a dispersion of keywords in some groups, which characterizes the low specificity of the research under consideration.

We can also mention the inequality of the distribution of the groups that work with wounds in terms of the geographical regions and states of Brazil, in that $42.6 \%$ of these groups are concentrated in institutions located in Southeast Brazil.

It is also possible to identify a number of relationships with the manufacturing sector. Based on this, it was identified that there is a limited potential with regard to generating patents leading to the production of biomaterials that could lead to an improvement in the quality of life of patients with wounds.

One limitation to this study is the fact that the scientific CVs of some researchers, at the moment of observation, were not in the Brazilian public open platform Lattes. This could jeopardize the analysis of the data, as the groups led by these researchers were excluded from the sample. Such a fact generated some thoughts, given that, since 2002, in order to integrate the Group and Lattes systems, it has become obligatory for researchers and students to register a scientific CV on the Lattes platform in order to register in the CNPq Directory ${ }^{(7)}$. The absence of a registered scientific CV and the presence of an outdated one harms the reliability of research in nursing.

\section{CONCLUSION}

The Directory of Groups of Research of CNPq is an important tool that offers a picture of research in Brazil. It is observed that, as yet, the nursing profession has a limited expression in research into the topic of wounds, in terms of the groups registered in the Directory, especially in pre-clinical studies, where it was seen that there were no groups working on this topic.

This important gap in the knowledge of nursing staff directs us to reflect about the formation of research into nursing in Brazil, where there is a focus on qualitative approaches over the quantitative ones. 
Nursing also has a limited integration in terms of the interdisciplinary research context, especially with regard to the topic of wounds. Such a limitation inhibits the visibility SEE ABOVE of the research produced by nurses in terms of other areas of knowledge.

\section{REFERENCES}

1.Leite AP, Oliveira BGRB, Futuro DO, Castilho SR. Effectiveness of using the gel of papain in the wound healing: clinical trial. Online braz $\mathrm{j}$ nurs [ serial on the internet ]. 2011 Oct [ cited 2012 May 10 ] 10 (2). Available from: http://www.objnursing.uff.br/ index.php/nursing/article/view/3351/html 1

2.Erdmann AL, Mello ALF, Andrade, SRS, Klock P. Funcionalidade dos grupos de pesquisa de administração/gestão/ gerência de enfermagem. 2010 Apr; Rev Rene. 11(2): 19-26.

3. Conselho Nacional de Desenvolvimento Científico e Tecnológico [ Homepage on the internet ]. Diretórios de pesquisa [cited 2012 May 16]. Available from: http://www.cnpq.br/gpesq/apresentacao.htm.

4.Erdmann AL, Lanzoni GMM. Características dos grupos de pesquisa da enfermagem Brasileira certificados pelo CNPq de 2005 a 2007. Esc Anna Nery Rev Enferm. 2008 Jun; $12(2): 316-22$.

5.Oliveira MAC. A interdisciplinaridade no ensino e na pesquisa em Enfermagem. Rev Esc Enferm USP. 2012 Apr; 46(2):01-2.

6.Cabral IE, Tyrrel MAR. Pesquisa em enfermagem nas Américas. Rev Bras Enferm. 2010 Jan; 63(1): 104-10.

7.Conselho Nacional de Desenvolvimento Científico e Tecnológico [ Homepage on the internet ]. Mudanças importantes introduzidas a partir de 2002 [ Cited 2012 Apr 23 ]. Available from: http://dgp.cnpq.br/censos/inf gerais/aquisicao arquivos/ central que eh.htm.

Received: $17 / 07 / 2012$

Approved: 28/01/2013 